\title{
HRJ
}

v.2 n.9 (2021)

Recebido: 20/09/2020

Aceito: $22 / 12 / 2020$

\section{Residência multiprofissional em saúde da família: tecendo sobre a conversão da lógica tradicional para Estratégia de Saúde da Família}

\author{
Daniela Sousa de Oliveira ${ }^{1}$ \\ Silvana Pereira Dantas Evangelista de Souza ${ }^{2}$ \\ Caroline Jonas Rezaghi Ricomini Nunes ${ }^{3}$
}

1. Terapeuta Ocupacional. Residente do Programa de Residência Multiprofissional em Saúde Mental do Adulto, Escola Superior de Ciências da Saúde - ESCS/FEPECS, Distrito Federal. Mestranda do Programa de Pós-Graduação em Saúde Coletiva, Universidade de Brasília - UnB. E-mail: aleinda21 @ gmail.com

2. Fisioterapeuta Especialista em Saúde Coletiva. Pós-Graduada em Fisioterapia DermatoFuncional. Residente do Programa de Residência Multiprofissional em Saúde Mental Infantojuvenil- ESCS/FEPECS. E-mail: silvana.dantas2705@gmail.com

3.Terapeuta Ocupacional. Especialista em Saúde Coletiva, Fundação Oswaldo Cruz - Fiocruz. Mestre em Ciências da Saúde pela Universidade de Brasília - UnB. E-mail: carolinejonasnunes@gmail.com

\section{RESUMO}

A Atenção Primária à Saúde (APS) é reorganizada em todo território nacional pela Estratégia de Saúde da Família (ESF), que visa cuidado ampliado e orientado nos territórios. A partir dessa temática, este estudo teve como objetivo aplicar oficinas como intervenção educativa, horizontalizada e participativa com os profissionais que passaram pelo processo de transição do modelo de atenção à saúde. Trata-se de uma pesquisa-ação com abordagem qualitativa e descritiva. Dessa forma, utilizou-se metodologia desenvolvida no formato de oficinas de sensibilização com trabalhadores de diferentes categorias profissionais. As oficinas foram gravadas, transcritas e categorizadas pela análise temática simples. Os resultados propõem que a forma como foi construído o processo de mudança de modelo de atenção à saúde causou distanciamento entre a gestão e os trabalhadores. Estes relataram não identificação com processo de trabalho imposto.

Palavras-chave: Atenção primária à saúde. Estratégia saúde da família. Capacitação em serviço. Modelos de atenção

\section{Multiprofessional residency in family health: weaving on the conversion of traditional logic to Family Health Strategy}

\section{ABSTRACT}

Primary Health Care (PHC) has been reorganized throughout the national territory by the Family Health Strategy, which aims at more extended and oriented care in the family and community. This study has a descriptive qualitative approach and aims to apply workshops as an educational, 
horizontal, and participatory intervention with professionals who were in the process of transition from the health care model. The methodology developed in the format of awareness workshops with workers from different professional categories. The workshops were recorded, transcribed, and categorized by simple thematic analysis. The results propose that the way in which the process of changing the health care model was built caused a distance between management and workers. The workers reported disidentification with an imposed work process.

Keywords: primary health care. family health strategy. in-service training. models of attention

\section{INTRODUÇÃO}

Criado em 1996, o Programa de Saúde da Família (PSF) permitiu ampliar a cobertura de atenção à saúde à população brasileira com foco nas questões sociais e de vulnerabilidade ${ }^{1}$. Essa configuração permitiu a organização dos processos de trabalho com enfoque no território ${ }^{1}$. Em 2002, visando reorientação do modelo de atenção e expansão dos serviços da Atenção Primária de Saúde (APS), foi lançada a Estratégia de Saúde da Família (ESF) com a compreensão da saúde da família como plano acessível de cuidados em saúde ${ }^{1}$. A APS é o primeiro nível de acesso e realiza coordenação, orientação dos fluxos de usuários que buscam atendimento, tendo em vista as ações de base comunitárias, parte de ações voltadas para atenção longitudinal e continuada com acesso garantido pelo direito à saúde pela Constituinte Cidadã ${ }^{1}$.

Para Starfield (2002) $)^{2}$ a APS é definida como,

[...] aquele nível de um sistema de serviço de saúde que oferece a entrada no sistema para todas as novas necessidades e problemas, fornece atenção sobre a pessoa (não direcionada para a enfermidade) no decorrer do tempo, fornece atenção para todas as condicionantes, exceto as muito incomuns ou raras, e coordena ou integra a atenção fornecida em algum outro lugar ou por terceiros. Assim, é definida como um conjunto de funções que, combinadas, são exclusivas da atenção primária. A atenção primária também compartilha características com outros níveis dos sistemas que são de: responsabilidade pelo acesso, qualidade e custos; atenção à prevenção, bem como ao tratamento e a reabilitação; e trabalho em equipe. (STARFIELD, 2002, P. 28).

No Brasil, a APS se configura de forma descentralizada e regionalizada voltada para ordenação do cuidado, com ação centrada na prevenção e promoção de agravos com vistas às condições crônicas e agudas de saúde ${ }^{3,4}$. Fortaleceu-se com movimentos sociais, como a Reforma Sanitária da década de 1970 que trouxe uma visão integralidade e equidade ${ }^{3}$. Experiências somadas com a $8^{\text {a }}$ Conferência de Saúde de 1986 e reforma sanitária possibilitaram a implantação de uma APS que fizesse sentido aos princípios e diretrizes do SUS e que colocassem a população em contato com processo de cuidado, com vistas à participação social ${ }^{4}$. 
Entretanto, a publicação em setembro de 2017 da Política Nacional de Atenção Básica (PNAB) surge como com uma proposta de desfavorecimento prioritário a Estratégias de Saúde da Família que até o ano 2016 eram utilizadas como modelo a ser implantado em todas Unidades Básicas de Saúde que têm os serviços de APS. Regulamentada anteriormente pela Portaria GM nº. 648, de 28 de março de 2006 que caracterizou atenção básica, também denominada APS, como um conjunto de ações de saúde, individuais e coletivas, com objetivo de desenvolver uma atenção integral que impacte na situação de saúde, na autonomia das pessoas e nos determinantes de saúde. Essa proposta visa qualificação e consolidação da atenção básica, por meio da reorganização da atenção e reorientação do processo de trabalho, favorecendo a ampliação da resolutividade e do impacto na situação de saúde, além de propiciar uma importante relação custo-efetividade ${ }^{35}$.

No entanto, são poucas as regiões de saúde que se comprometeram com a implementação da ESF como estratégia significativa. O Distrito Federal (DF) apresentou durante muito tempo uma abordagem assistencial de baixa resolutividade, com condições precárias de trabalho, sem retaguarda de especialidades da área da saúde e desconectada da atenção hospitalar, além da baixa cobertura de ESF, de apenas 30,7\%, o que impactava negativamente na qualidade da atenção e no acesso aos serviços ${ }^{6}$, sendo resultado da coexistência de dois modelos diferentes de enfrentamento às problemáticas sensíveis à APS. Para melhorar esse quadro, foi lançado pelo governo do DF o Programa Brasília Saudável (PBS), um conjunto de ações para o fortalecimento da APS como estratégia de reorganização do sistema de atenção à saúde e porta principal de acesso ao Sistema Único de Saúde (SUS). Posteriormente foi criado, com base no PBS, o ConvertDF ${ }^{6}$.

O ConvertDF foi dimensionado para ocorrer de forma progressiva até 2018 nas Regiões de Saúde definidas no Decreto $\mathrm{n}^{\circ} 37.057$, de 14 de janeiro de 2016. Iniciou-se no primeiro ano com a proposta de conversão de parte dos Centros de Saúde Tradicionais do Distrito Federal em Clínicas da Família, exclusivamente com a Estratégia de Saúde da Família, com equipes completas e contemplava no projeto reformas na infraestrutura das unidades ${ }^{6}$. O ConvertDF teve o objetivo de que todas as equipes que trabalhassem no modelo tradicional biomédico fossem convertidas para 
ESF, de base comunitária, com a expectativa de cobertura universal de $72 \%$ até o final do ano de $2017^{6}$.

Por meio de duas portarias, a Secretaria de Estado e Saúde do Distrito Federal (SES-DF), oficializou as mudanças com as Portarias $n^{\circ} 77$ e 78/2017, dessa forma, reconheceu a necessidade de reestruturação da APS como ordenadora da atenção à saúde no território e como porta de entrada preferencial do SUS, visando atingir $75 \%$ de cobertura da população do DF com a ESF. Entretanto, para que isso acontecesse, as equipes mistas e tradicionais precisariam aderir ao processo de transição, para então serem capacitadas com intervenções teórico-práticas. Ofertou-se a decisão de continuar na APS ou transferência para outros níveis de atenção à saúde do DF. Os trabalhadores que optaram em permanecer foram capacitados para ações educativas de mudança de especialidade de atuação na SES-DF, caso aprovados, no final, por exemplo, os médicos receberiam nomeação de Médico de Família e Comunidade ${ }^{67}$.

As portarias estabeleceram como iriam funcionar a conversão das equipes e a regulamentação da Política de Atenção Básica no DF. As equipes tradicionais biomédicas que se submeteriam à capacitação teórico-prática iriam ser transformadas em Equipes de Transição Saúde da Família (ETESF), como forma de organizar e centralizar os processos educativos. As equipes de ESF, que dividiam o mesmo espaço das ETESF, seriam responsáveis por matriciar quanto aos processos de trabalho e atributos da ESF, de acordo com as prioridades nas áreas de maior vulnerabilidade social ${ }^{6}$. Uns dos principais desafios para a ESF foi a questão dos recursos humanos, sendo necessárias uma reorganização e qualificação do processo de trabalho. Estratégias educativas podem contribuir para o enfrentamento de problemas de saúde de forma a melhorar o acesso, a qualidade do atendimento prestado e a resolutividade. Assim foram necessárias ações de capacitação, formação e educação permanente de profissionais de saúde para atender aos princípios e às diretrizes organizativos da Política Nacional da Atenção Básica e, por consequência, aumentar a capacidade resolutiva da atenção neste nível do sistema ${ }^{89}$. 
As intervenções educativas propostas neste trabalho se inserem no contexto do processo de conversão da atenção primária do DF para o modelo de ESF, contribuindo para a construção e o aperfeiçoamento do perfil do cuidado oferecido pelas equipes de saúde da APS. Nesse contexto, como forma de colaboração com ações de educação continuada e permanente, a primeira refere-se a atividades educativas para atualização, sendo uma oportunidade para desenvolvimento de habilidades e melhor desempenho das funções no dia a dia. Já a educação permanente, instituída em 1978, pela Organização Pan-Americana de Saúde (OPA), refere-se a um processo dinâmico de ensino e aprendizagem contínuo com o objetivo de melhorar a capacidade de respostas frente à evolução tecnológica, tendo em vista as metas institucionais estipuladas. Como forma de normatização dessas práticas educacionais, em 2004, foi criado a Política Nacional de Educação Permanente em Saúde (PNEPS), que define a educação permanente como "aprendizagem no trabalho, em que o aprender e o ensinar são incorporados ao cotidiano dos serviços e aos processos de trabalhos, esquematizados a partir de problematizações"10.

Em meio ao processo de transformação do modelo de atenção na APS, a Residência Multiprofissional em saúde da Família inseriu-se na Diretoria Regional de Atenção Primária à Saúde (DIRAPS), com incumbência de construir e propor um projeto suplementar ao ConvertDF com perspectiva de alcançar as singularidades, enfrentamentos e possíveis desafios locais que estivessem dificultando a transição de modelo. Diante disso, foi proposto logo após consulta informal com trabalhadores de duas UBS de Ceilândia-DF, um ciclo de oficinas de sensibilização com foco na capilaridade, acolhimento e um espaço para reflexões críticas, visando descrever a participação e compreensão desses trabalhadores sobre o modelo de base comunitária - ESF do qual se trata este estudo. Contudo, o processo de conversão do modelo de atenção à saúde na APS no DF foi um momento singular com importância para o melhoramento dos serviços prestados à população, que antes tinham enfoque nas queixas e ações meramente preventivas e, com a oportunidade de ESF, tornaram a olhar para questões sociais e de vulnerabilidade e principalmente para realidade de cada território, o que não é trabalho fácil de desempenhar, visto que a capacitação 
das equipes acostumadas ao trabalho tradicional biomédico justifica-se primordialmente para superação da modelo hegemônico e curativo ${ }^{7}$.

\section{METODOLOGIA}

Trata-se de um estudo com abordagem qualitativa de caráter descritivo com a perspectiva da pesquisa-ação, em razão de não haver separação do "sujeito-objeto, neutralidade científica, generalização, manipulação de variáveis, mas que visa compreender os fenômenos estudados sob a ótica dos participantes", pois a pesquisa qualitativa objetiva conhecer o ambiente natural ${ }^{11}$. No tocante à perspectiva da pesquisa-ação, segundo Neves (2006), é uma proposta intervencionista que surge a partir da necessidade de planejar soluções pontuais sobre determinadas problemáticas de um coletivo, no qual os atores do processo se juntam de forma participativa para construções de estratégias e respostas às demandas identificadas ${ }^{11}$. A pesquisa-ação tem caráter crítico-reflexivo que se apoia no desenvolvimento do processo educativo. Permite "a transformação da realidade investigada e a produção do conhecimento" ${ }^{12}$.

O estudo foi desenvolvido em duas Unidade Básicas de Saúde (UBS) que estavam no processo de conversão do modelo tradicional para o de base comunitária, advindo da implantação do ConvertDF. Como forma de aproximar e promover um ambiente de partilha e transformação do ambiente, foram utilizadas quatro técnicas de processamento das informações: oficinas de sensibilização, entrevistas semiestruturadas, observação dos participantes e o diário de campo. Este artigo se organiza em trazer as informações relativas às oficinas de sensibilização, as quais foram gravadas com gravador de voz, transcritas e submetidas à análise de conteúdo. Segundo Galvão (2018) ${ }^{13}$ este é um meio mais trivial de processamento e transformações das informações. Trata-se de um procedimento simplificado que abrevia um fenômeno com grande conteúdo a relativamente pequenas categorias ${ }^{11}$. As oficinas de sensibilização caracterizam-se pela relação dialética por oportunizar espaços de interação e troca de saberes dentro de uma coletividade. São marcadas pela horizontalidade na construção do conhecimento e reconhecem a democracia como elemento disseminador de práticas participativas. Têm a proposta de "estreitar a distância entre teoria e 
prática, entre o conhecimento e trabalho e entre a educação e a vida" ${ }^{14}$.

Foram realizados cinco encontros com duração média de $2 \mathrm{~h} 30$ em duas UBS de CeilândiaDF. Em cada unidade, os participantes foram divididos em dois subgrupos, um no período da manhã e outro no período da tarde. Ou seja, o estudo contou com quatro subgrupos, dois em cada UBS. A amostra total das duas UBS somou 45 trabalhadores, houve três desistências. Os trabalhadores envolvidos no processo foram: médicos, enfermeiros, agentes comunitários de saúde, técnico em enfermagem, profissionais do administrativo, porteiros e serviços gerais.

As oficinas foram organizadas da seguinte forma: a primeira foi estruturada como proposta de sensibilização, construção de contrato de convivência e apresentação da proposta. Os participantes tiveram oportunidade de formular propostas a serem incluídas no planejamento temático. O objetivo foi identificar questões do cotidiano que precisariam ser problematizadas no contexto de conversão do modelo de atenção à saúde e sensibilizá-los quanto à proposta intervencionista. A segunda tratou sobre os processos de trabalho centrado na comunidade, o objetivo foi promover reflexões acerca do modelo tradicional e do ESF, como também fomentar discussões sobre humanização, classificação de risco e o acolhimento. A terceira, intitulada como "saindo das quatro paredes com vistas à saúde integral", teve a finalidade de promover sensibilização quanto aos termos de acolhimento e triagem baseados na Política Nacional de Humanização, trabalhar questões sobre território com suas transversalidades como: cadastramento e o controle social. A quarta oficina teve como proposta trabalhar o desenvolvimento de processo de trabalho pautados na perspectiva do trabalho vivo, com finalidade de construir forma de organização da rotina e dos fluxos de atendimentos focados nas necessidades dos usuários. E consequentemente o trabalho em equipe e introdução de tecnologias leves nos processos de cuidados, com destaque para parceira com o Núcleo Ampliado de Saúde da Família e atenção básica (NASFab). A última oficina, quinta, foi estruturada em formato mais aberto que as demais, com a finalidade de oferecer além de um espaço de construção de estratégias cotidianas que respondam aos desafios impostos pela instituição do modelo de base comunitária, proporcionando 
um momento de confraternização.

Por meio de análise de conteúdo, que permite ao pesquisador a construção de categorias a serem analisadas, foi possível fazer desmembramento em três grupos: "processo de trabalho", "modelo de base comunitária" e "modelo biomédico". Destaca-se ainda que não existem "regras" tanto para a nomeação das categorias, quanto para a determinação do número de categorias ${ }^{15}$. As narrativas foram identificadas a partir da ordem de fala em cada oficina e criadas em conformidade com a subjetividade do pesquisador, como apontado, trazem três momentos importantes identificados pelas pesquisadoras ao longo do estudo, representando as impressões acerca da realidade que estava em debate. As narrativas são o resultado das codificações do ciclo de oficinas e representam a síntese das informações coletadas. Este estudo foi aprovado no Comitê de Ética em Pesquisa da Fundação de Ensino e Pesquisa em Ciências da Saúde - FEPCS, em acordo a Resolução no 196, do Conselho Nacional de Saúde, CAAE: 73150017.6.0000.5553.

\section{RESULTADOS E DISCUSSÃO}

As informações apresentadas a seguir referem-se ao processamento e à categorização da análise de conteúdo. Os participantes foram nomeados com a letra "P" seguida de um número para distingui-los e, assim, não revelar a identidade dos envolvidos no estudo. A decodificação gerou três categoriais as quais foram denominadas em: "processo de trabalho", "modelo de base comunitária" e "modelo biomédico".

\section{PROCESSO DE TRABALHO}

O processo de trabalho na APS configura-se, segundo Fontana $(2016)^{16}$, como um conjunto de ações coordenadas desenvolvidas pelos trabalhadores em que se compõe objeto de trabalho a junção dos "saberes e métodos que refletem as combinações tecnológicas para alcance dos objetivos, saberes e instrumentos" ${ }^{16}$. As oficinas identificaram que há desconexão entre o que o gestor da UBS espera de resposta do trabalhador com que os trabalhadores entregam. Os participantes relataram a existência de ruídos na comunicação e que existem poucos espaços deliberativos, já que a proposta de implantação da ESF necessita de trabalho personalizado e 
colaborativos, torna-se difícil não haver clareza na comunicação. Pois assim como os trabalhadores, os gestores também teriam que se adequar à realidade do modelo de ESF que exige uma ruptura dinâmica nos microprocessos de trabalho em saúde ${ }^{17}$.

[...]E o problema é muito fácil de resolver, só precisava dialogar com o servidor. É muito simples. Só precisava dialogar $(P 2)$.

[...]Antigamente a gente tinha a oportunidade de chegar ao nosso gerente e desabafar. Porque o cargo de chefia estar para acolher todas as demandas do servidor. Hoje a gente vê que cargo de gerente não é mais assim. Se você desabafar, você vai ser marcada. A posição do gerente é de acolher (P6).

[...]A horizontalidade não existe, existe a verticalização, essa é a verdade. Se você fala, eles dizem que você reclama demais (P12).

Resultado semelhante foi observado na pesquisa-ação realizada por Silveira et al. (2010) ${ }^{18}$ em que a comunicação da gestão era improvisada, inadequada e não alcançava os trabalhadores e consequentemente a população. Os pesquisadores apontaram que existe uma carência na estruturação da gestão do trabalho, educação, informação e comunicação em saúde. Nesse sentido, o presente estudo destaca a necessidade de implementações em estratégias de educação e difusão de novos conceitos e práticas para gestão com vista a efetivar mudanças gerenciais para fortalecimento da autonomia e incentivo do planejamento local e participativo ${ }^{18}$. Os profissionais de saúde das UBS reconhecem que a comunicação é uma ferramenta importante na organização de ações e serviços no cotidiano da UBS e que a construção do diálogo deve ser por ações horizontalizadas, uma vez que a não sincronia das informações podem causar conflitos interpessoais e interpretações equivocadas. Houve relatos de descontentamento com trabalho, o que revelou falta de identificação do profissional com o seu processo de trabalho. Tal situação ocorre no modelo organizativo taylorista, que padroniza e burocratiza o serviço ${ }^{19}$.

[...]Uma coisa é a teoria outra coisa é prática, né? Se tem um ser que não tem um mínimo de valor, esse é o servidor. Já tivemos dias melhores, mas, nunca foram tão ruins! Antes, pelos menos tínhamos certo respeito pelos gestores. Agora não tem nada de transversal, é totalmente vertical. É igual passar sonda, né? Enfia a garganta abaixo e nem quer saber o que tem pelo caminho, o se o sujeito aguenta ou não. Mas que vai, vai! Eu acho muito irônico. De repente a gente se torna descartável (P17).

[...]Com todas essas faltas de transparências e de clareza. Fala-se tanta, em vínculo com comunidade, e que a gente tem que trabalhar em conjunto. Mas os nossos gestores não trabalham em conjunto conosco, ou seja, o vínculo é zero. E quando se já tem um vínculo, como aqui a gente tinha. Mesmo que pequeno o vínculo, que era o tal do modelo tradicional. Foi quebrado. E hoje nos cobram esse vínculo? A própria gestão não trabalha com isso, e não dá oportunidade de a gente falar (P13).

Foi identificado nos relatos sobre a hegemonia e infiltração do taylorismo nos processos de 
trabalho do modelo tradicional, que reduz consideravelmente trabalhadores a instrumentos e técnica sem a sensibilidade e singularidade necessária na APS. Que tem resultado na quebra com a autonomia e iniciativa crítica dos trabalhadores, além de estar centralizado na figura do chefe ${ }^{19}$. Neste modelo a padronização é essencial para operacionalização do trabalho cotidiano, uma vez que o trabalhador deve apenas executar ações sem desenvolver reflexões críticas do processo, a chamada "unidade de produção" ${ }^{19}$. Esse modelo além de hierarquizar os processos de trabalho também causa fragmentação e distanciamento significativo entre o gestor e o trabalhador, uma literatura aponta para construção de gestões compartilhadas e de cogestão. Com intuito de promover estreitamentos da concepção de uma ideia a tomada de decisões, o que gera maior implicação, identificação e satisfação com trabalho, além de proporcionar desenvolvimento crítico e reflexivo ${ }^{19}$.

Há um entendimento no imaginário dos trabalhadores a respeito do que se chama de “cogestão" ou "gestão compartilhada", na tentativa de ressignificar o processo de trabalho a partir do compartilhamento de ideias, uma vez que as discussões nas oficinas revelaram um sentimento de exclusão, por parte dos profissionais. Nota-se também um desejo de reconhecimento no trabalho, com vistas à satisfação e à visibilidade. Os trabalhadores fizeram citação quanto ao distanciamento entre teoria e prática, em virtude de não conseguirem aliar os interesses da gestão e dos trabalhadores que estão na ponta ${ }^{20}$.

[...]As pessoas que estão por trás disso nunca nem vieram aqui. Não conhecem nossa realidade, não conhece nada. E fica uma sensação de omissão. Como se a gente estivesse sendo punido. Então, as coisas são mal feitas desde o início; infelizmente a gente vive dentro de uma falsa democracia. A gente tem que cumprir as coisas e não adianta muito você, também, vir depois discutir, por quê? Se já foi feita, né? Não vai ter valor, nem peso a sua fala (P60).

[...]Estamos seguindo na melhor forma que pode, porque, nós, servidores, se doam muito! Só que a gente não é olhando como o servidor que está se doando. Teoria é muito fácil, agora o dia a dia? (P23).

A falta de acompanhamento de conhecimento da realidade da UBS foi ponto muito discutido entre os trabalhadores que participaram das oficinas, no qual fazem relação a falta de alinhamento entre o planejamento e a execuções das ações e serviços nas UBS. Campos (2007), em seu estudo, compara a prática e a teoria quando identifica obstáculos estruturais em ambas, classifica-os como "obstáculo político e de comunicação" tem maior ocorrência entre trabalhadores 
e gestores $^{21}$. A concentração do poder na gestão é um desafio para o Sistema Único de Saúde do Brasil, um ponto pelo qual ainda é merecedor de instalação de ações de ruptura que enfraqueçam esse tipo de relação. Essa concentração de poder tem provocado estagnação, desarticulação e fragmentação do trabalho. A construção partilhada é um processo complexo, mas, que possibilita melhor visualização dos projetos a serem implementados e ampliação do olhar dos trabalhadores quanto às questões sociais, estruturais e organizativas dos territórios de saúde. Campos (2007), afirma que a construção de "equipes colegiadas com poder deliberativo" é uma alternativa que pode estimular o protagonismo dos trabalhadores quanto à construção de espaços coletivos para o "estabelecimento de cogestão e de democrática institucional"21. A não inclusão dos trabalhadores nos momentos de elaboração de projeto e assim como nas tomadas de decisões oportuniza um distanciamento generalizado. Os trabalhadores relacionaram a boa convivência e respeito como sendo algo primordial nas relações entres e eles e os gestores ${ }^{20}$.

[...]Vejo que a gente cria muita expectativa, para uma coisa muito mais para a frente. E que a gente tem que pensar devagarzinho, né? (P5).

[...] Outro problema é a falta de funcionário, né? Um dia tem funcionário e outro não. E gente não consegue fechar um único dia com escala completa (P31).

[...]Eu acredito que a proposta é excelente, ninguém achou ruim a ESF. O que nós não acreditamos é a forma de implantação. Se esse processo, aqui, de vocês tivesse sido feito antes, você poderia pegar o servidor mais motivado para a mudança. E hoje vocês pegam os servidores revoltados. Então, se no início tivesse sido feita roda de conversa. Onde o servidor foi totalmente colocado de lado. A culpa do sistema estar falido é do servidor? Sendo que é momento que precisa do apoio dos servidores (P22).

As grandes mudanças relatadas pelos trabalhadores sobre o processo de trabalho estão relacionadas à falta de estrutura e de comunicação, e o alinhamento entre o que a gestão quer e o que os trabalhadores conseguem executar com os recursos que têm. Esmeraldo (2017) ${ }^{22}$ em seu estudo também percebeu que existe um distanciamento entre esses dois atores, e para melhor atuação na ESF são necessárias pactuações que alcancem os desejos e percepções de todos, para possibilitar novas formas de se fazer gestão de modo que os processos de trabalhos das equipes possam estar em consonância com realidade das comunidades e diretrizes da ESF, no sentido de pensar saúde dentro de conceito de longitudinalidade de forma coordenada e com uma rede fluida e acessível $^{22}$. Portanto, o processo de trabalho no contexto da ESF é caracterizado por ações e 
serviços singulares que expressam na produção cotidiana as subjetividades, alinhamento entre a gestão e os trabalhadores, a fim de que o objeto do processo de trabalho possa ser um meio de transformação das realidades e alcance a população ${ }^{17}$.

\section{MODELO DE BASE COMUNITÁRIA}

As planificações do modelo APS no DF não começaram com o ConvertDF. Desde 1994 a 1998, as mudanças foram arranjadas em decorrência das visões políticas. A implantação do Programa Saúde em Casa (PSC) com desenho do PSF, regido pelo modelo biomédico, e do Programa de Agentes Comunitários de Saúde (PACS), foram mudanças que impuseram formas de organização da APS que objetivaram pela primeira vez a ideia de cobertura integral da população e os modelos assistenciais focados no território ${ }^{23}$. A ESF que objetivava implantação no DF é reconhecida como primeira atenção à saúde do nível do SUS com a característica de ser ampla nas especificidades e capilarizada quanto às singularidades do território. Sendo assim, nota-se um modelo que reorganizou a APS, levando em consideração os princípios dos SUS: integralidade, universalidade, equidade e controle social ${ }^{24}$.

Detém de um arranjo organizacional que foge da hierarquização, da padronização e da mecanização, tem refinado a estrutura de trabalho compartilhado e de cogestão. Dá oportunidade de criação de espaços de reflexão e entendimento das necessidades da população, como exemplo, ao elaborar um Projeto Terapêutico Singular (PTS), que é uma ferramenta de articulação das condutas terapêuticas, dentro da perspectiva multiprofissional e interdisciplinar, pois geralmente é um momento no qual a equipe compartilha opiniões e saberes com proposta de ajudar a entender o caso e consequentemente definir as intervenções de curto, médio e longo prazo ${ }^{24}$.

[...]Fazer um PTS para o seu Joaquim vai ser muito bom, mas a cobertura vai ficar muito aquém, sabe? Porque eu vou deixar de atender umas sete pessoas. Porque nós poderíamos estar produzindo atendimento com um volume muito maior. É fantasioso em uma parte, porque a questão é recurso, e produtividade! Porque é um território de mais 3750 pessoas. Até agora eu não vejo diferença no atendimento que foi dado a Joaquim, que é o mesmo do tradicional, né? (P10).

[...]Aí a gente fica igual àquela criança que você bate nele todos os dias. O dia que você toca na mão dele para fazer um carinho ele vai gritar. Ele vai achar que vai apanhar. Então esse serviço 
que está sendo feito agora, essa mudança do tradicional para ESF, talvez seja até uma boa, mas, para a gente que está aqui embaixo, temos o entendimento que é outro castigo que estamos sofrendo, que de repente não vai dar certo. Vai ser ruim, vai trazer sofrimentos para a gente, profissionais. Porque a gente vem apanhando, né? A gente tem como uma pena a ser cumprida (15).

Há reconhecimento entre os trabalhadores que a implantação da ESF deve ser antecipada por algumas melhorias, como os recursos humanos. Também revelaram certa dificuldade e rigidez em configurações de trabalho preconizados pelo modelo tradicional. Observa-se o enraizamento do modelo biomédico, ainda forte no processo de trabalho desses profissionais. Um modelo que provoca separação, detenção do poder na figura do médico, abordagens focadas na doença e distanciamento da gestão. Uma questão importante a ser colocada é que os trabalhadores reconhecem que o modelo tradicional não cabe mais nas concepções de saúde que vigoram atualmente. No entanto, há uma grande dificuldade de se colocar em prática concepções que podem tirá-los do manejo cômodo da rotina, mesmo que fique claro que o isolamento, no caso da sala da vacina, por exemplo, provoque, além de uma ineficiência, um isolamento dentro da própria UBS, que reconhece como taylorismo ${ }^{25}$.

Trata-se de um contraponto no qual o trabalhador demonstra estar inserido no modelo estático, não sendo capaz de produzir trabalho vivo, ou seja, um trabalho crítico reflexivo, no qual as relações são compartilhadas, ele deixa de ser apenas um operário e passar a conceber ideias e proposta de trabalhado integralizadas as suas habilidades as necessidades singulares dos territórios, passa a ter um papel parecido com mestre de obras o que planeja, articula e executa. Verifica-se que, além de introdução de tecnologias, precisa-se antes de qualquer ação, afeto, para que se possa resgatar o ressignificar cotidianamente ${ }^{25}$.

[...]Porque a gente vê que a realidade é bem diferente. Não é pela implantação da ESF que vai melhorar. Mas a falta de compromisso dos servidores, falta de recursos humanos, apoio da gestão que vai fazer melhor. Tanto faz o modelo que se empregue! (P19). Vacina tem que ter um manejo adequado. Tem uma série de questões que precisa de uma rotina estabelecida, sem isso não funciona. Eu ouvir isso várias vezes de rodízio, e eu digo que não funciona (P3).

Os trabalhadores relataram dificuldades de identificar diferença entre o modelo tradicional e o da ESF. Colocam-se na posição de promotores da saúde e o usuário na posição de paciente. Relataram que não há informações concretas sobre o modelo a ser implantado e justificam em 
função da rigidez da adesão na implantação da ESF, a falta de informação e o histórico de tentativas de implantações de outros modelos no $\mathrm{DF}^{22}$.

Outro ponto bastante discutido nas oficinas de sensibilização estava relacionado à reunião de equipe, sendo um momento de trocas essencial dentro das propostas da ESF, uma vez que permite proximidade nas relações entre as equipes, desenvolvimento de habilidades e acompanhamento integral dos usuários dos serviços. Os trabalhadores fazem referência à reunião como algo importante e argumentam que o modelo tradicional não favorece uma produção de conhecimento crítico-reflexivo, o que tem provocado descaracterização da reunião como algo que traz algum tipo de punição. Relatam a necessidade de voltar à essência e instalar a democracia e a horizontalidade nas tomadas de decisões ${ }^{26}$.

[...]Reunião nunca veio para dá um elogio, nunca veio para ser boa. Reunião veio para discutir um monte de coisa que não chega a lugar nenhum (P2).

[...]As reuniões são só para comunicar decisões que já foram tomadas. Fica todo mundo muito confuso e no final ninguém sabe de nada (P4).

[...]As reuniões, aqui, são só para um determinado grupo de servidores. A vacina vai ser só para o pessoal da vacina; curativo, só curativo; grupo de diabete, só para o grupo de diabetes (p7).

Os trabalhadores defendem a ideia de fragmentação com vistas a uma organização "prática", não apenas na teoria. Conforme observado, a separação de forma setorial, na visão dos trabalhadores, não é uns dos impasses que tem causado a falta de resolutividade ditada pelo modelo biomédico. Os trabalhadores também revelaram falta de conhecimento quanto à proposta de base comunitária que oportuniza de forma fluida o acolhimento e a desburocratização. No entendimento de alguns, a proposta de ESF não tem diferença com o modelo que vigora, o biomédico ${ }^{22}$.

[...]Eu já me sinto médico de saúde da família há muito tempo, porque eu entro nas casas sem nunca ter ido lá. Porque eu tenho acesso ao estado de saúde da família completa! (p11).

[...]Nós temos muitos pacientes fiéis aos médicos. E isso é um problema (p21).

A supervalorização dos procedimentos médicos é entendida pelos trabalhadores como sendo uma ação resolutiva de cuidado, o que subsidia o contato e vínculo que ocorre pela instrumentalização de procedimentos como: solicitação de exames laboratórios, de imagens e encaminhamentos a especialistas como forma de trabalho duro ${ }^{27}$, uma vez que deveriam estar atentos às necessidades subjetivas, assim como a ações voltadas às vulnerabilidades sociais e 
focadas ao sujeito singular e íntegro. A valorização do atendimento médico centrado tem demandado um aumento para medicina investigativa, em que em muitos casos caberiam dispensa da realização de alguns procedimentos. Uma linha de pensamento, justificada pelos trabalhadores, que tem criado um inchaço nas redes de atenção à saúde, pois muitas vezes esses procedimentos são desnecessários ${ }^{28}$.

[...]A comunidade tem esse conceito, de quem vai resolver é o médico. Alguns profissionais se acomodam, porque é menos trabalho, outros tentam, tentam, tentam que não conseguem ter uma resposta muito positiva (p.26).

[...]Teve um senhor que chegou outro dia dizendo que o serviço estava ruim e que era culpa era nossa. Só nossa? A gente está que nem uma salsicha do cachorro-quente, de um lado o governo falando que a gente não presta e do outro a população sem atendimento revoltada, eu até entendo. E ela escuta o governo dizer que é a gente não trabalha. E gente fica sem ter para onde ir (p.13).

Os contrapontos entre os modelos de atenção à saúde vêm se desmembrando de forma não vantajosa na desconstrução reflexiva de um modelo idealizado por uns e construído por poucos. O envolvimento dos trabalhadores ainda é sutil diante das resistências observadas nas oficinas de sensibilização, e isso pode estar corroborando para instituição de estigmas ilegítimos no modelo de base comunitária. Não há dúvidas sobre o entendimento e a compreensão das diferenças nos modelos de atenção à saúde para os trabalhadores, no entanto, essa resistência está mais ligada à insubmissão aos gestores do que à proposta do modelo ESF, que por muitas vezes foi alvo de elogios nos quatro grupos das oficinas. Possivelmente a separação dos trabalhadores no planejamento e tomada de decisão tem colocado o modelo ESF refém do modelo hegemônico, ancorando a garantia de acesso aos serviços, o atendimento integral, as ações de equidade e o envolvimento comunitário. Evidencia-se mais a existência de oposição quanto à forma como foi implementada a conversão do que a negação idealizadora do modelo de $\mathrm{ESF}^{7}$.

[...] o modelo de ESF está sendo muito impulsionado. Com uma força que foge dos profissionais, sendo deveria inserir o profissional no processo decisório (P7).

[...] Eu acredito que a proposta é excelente, ninguém acho ruim a ESF. O que nós não acreditamos é a forma de implantação. Se esse processo, aqui, de vocês tivesse sido feito antes, você poderia pegar o servidor mais motivado para a mudança. E hoje vocês pegam os servidores revoltados. Então, no início que deveria sido feita roda de conversa. O servidor fica totalmente desagregado $e$ colocado de lado. A culpa do sistema estar falido, é do servidor? Sendo que esse momento que precisa do apoio dos servidores. Já estar fadado ao fracasso! (p4).

[...]É um processo de adoecimento. É um massacre, esse nos nossos sentimentos. Eles afundaram a gente num processo de adoecimento que não nos consultaram se queríamos participar. A gente não tinha que passar por isso, sabe? Isso é um cala-boca que foi dado para nós(p28).

[...]A realidade é bem diferente. Não é pela implantação da ESF que vai melhorar. Mas o 
compromisso dos servidores, ter recursos humanos e apoio da gestão que vai fazer melhorar. Tanto faz o modelo que se empregue ( $p 8$ )

O processo de implantação da ESF como modelo de atenção prioritário na APS do DF constituiu-se na inclusão dos trabalhadores apenas no processo de execução, o que gerou um impacto significativo naqueles que aderiram ao modelo. Segundo Corrêa $(2019)^{7}$, houve quatro etapas que anteciparam a participação dos trabalhadores da ponta. A primeira estava relacionada ao "preparatório", que foi o momento de análise da distribuição dos serviços e das demandas da população atendida; a segunda foi a "elaboração e preparação", um momento para discussões nos Conselhos de Saúde e proposição para a Resolução CSDG n ${ }^{\circ} 465$, de outubro de 2016, que apontava uma APS sob modelos de ESF; a terceira etapa, “normatização e divulgação”, houve as construções das portarias que estabeleceram a política de APS no DF e conversão do modelo tradicional para ESF; e a quarta etapa foi o momento de capacitações teórico-práticas, no qual ocorreu a participação integral dos trabalhadores que permaneceram na APS. Os trabalhadores relacionaram a implantação da ESF como uma forma de punição, pois uns dos motivos dito sobre a conversão do modelo foi a falta de resolubilidade, no entanto, reconheceram que a ESF é proposta que mais se aproxima com demandas da população ${ }^{7}$.

\section{MODELO BIOMÉDICO}

O modelo tradicional biomédico é centrado na doença e na cura, essas práticas não correspondem à expectativa de cuidados em saúde da população, visto que esta precisa de uma atenção voltada para necessidades contextuais e não simplesmente assistenciais. O modelo é considerado pela literatura, ultrapassado, com baixa cobertura de resolubilidade, ineficiente na longitudinalidade e na integralidade do cuidado. No contexto desta pesquisa, nota-se que o modelo biomédico se tornou barreira de acesso aos serviços e ações da APS. Destaca-se a irresponsabilidade quanto à territorialidade e foco na queixa-conduta. O modelo biomédico é descrito como sendo um modelo de atenção a saúde que está em declínio pois se restringe apenas a doença e não o âmbito biopsicossocial, uma vez que o modelo de base comunitária, ESF, se propõe um olhar ampliado sobre as concepções de saúde que considera os determinantes e condicionantes 
de saúde ${ }^{22}$.

Outro ponto relatado pelos participantes das oficinas foi a incerteza sobre o futuro em relação à inserção profissional que tem colocado os trabalhadores na defensiva, ainda mais quando a prática de muitos anos no modelo tradicional biomédico é objeto de questionamento diante do modelo da ESF, que ainda não faz parte do cotidiano destes. Durante as oficinas, os trabalhadores relacionaram o acolhimento com a triagem em comparação do que ocorria nas equipes ESF. O Caderno de Atenção Básica $n^{\circ} 28$ define acolhimento como "uma prática presente em todas as relações de cuidado, nos encontros reais entre trabalhadores de saúde e usuários, nos atos de receber e escutar as pessoas, podendo acontecer de formas variadas" ${ }^{29}$. Portanto, o acolhimento envolve não só o momento pré-consulta, popularmente chamada de triagem, como também a escuta qualificada e classificação de risco, que na APS leva em consideração também os fatores de vulnerabilidade. No entanto, para os trabalhadores que estão imersos no modelo tradicional, há o equívoco entre triagem e acolhimento e ainda questionaram ser possível diante de uma rotina tão intensa de uma $\mathrm{UBS}^{29}$.

[...]Acolhimento é feito pelo técnico né? Não, pelo enfermeiro ( $p 7)$.

[...]Acolhimento é de qualquer pessoa, gente! (p30).

[...]Depende, porque esse acolhimento que está sendo feito aqui, de quem vai ser atendido ou não, é triagem ( $p 6)$.

[...]A triagem é a parte técnica faz, né? Que é aferir a pressão, glicemia. E faz uma separação do paciente que vai consultar do que não vai consultar. E o paciente só vai passar para o médico se passar pelo acolhimento ( 1919$)$.

[...]O acolhimento é o conjunto maior, dentro dele tem triagem, classificação de risco ( $p 8)$.

Lançada em 2004, a Política Nacional de Humanização estabelece ações para diminuir as barreiras de acesso e aproximar o profissional da população de seu território adscrito ${ }^{30}$. A efetivação da humanização como princípio ainda é um desafio. Apesar da presença de práticas humanizadoras nos serviços de saúde, estas não conseguem produzir melhoria no serviço ofertado quando não há uma reflexão mais aprofundada dos processos de trabalho e educação permanente com os profissionais $^{31}$.

Nota-se que a humanização, enquanto ferramenta, ainda precisa ser melhorada e discutida com trabalhadores para orientar sua prática. Espera-se que o acesso garantido não seja sinônimo de 
uma consulta com apenas um profissional especialista, mas que venha a valorizar as diferentes especialidades da equipe, o trabalho multiprofissional e interdisciplinar, garantir o direito dos usuários e promover uma gestão compartilhada ${ }^{31}$. Dessa forma, a transição do modelo para ESF parece favorecer o acolhimento, apesar das dificuldades de sua implementação na prática, como observado no estudo de Caldeira (2010) ${ }^{32}$, em que se identificou, por meio do instrumento de Avaliação para Melhoria da Qualidade da Estratégia Saúde da Família (AMQ), uma correlação positiva entre consolidação do novo modelo e melhoria da qualidade da assistência ${ }^{32}$.

Dados semelhantes foram observados em uma revisão integrativa sobre acolhimento na ESF, na qual, apesar de serem observadas mudanças na concepção teórica de acolhimento, como espaço de escuta das necessidades do usuário e a responsabilização do serviço de saúde pelas demandas identificadas, observou-se no cotidiano de algumas ESF a concepção de profissionais que identificam o acolhimento como triagem e como uma atividade voltada para a consulta médica ${ }^{33}$. A potência do modelo tradicional e sua padronização são descritas pelos trabalhadores com certa insegurança quanto ao modelo a ser empregado.

[...]Antes era tudo mais organizadinho. Tinha a sala da criança, as consultas periódicas, a sala da mulher, o pré-natal, a marcação de planejamento família, as palestras do hiperdia, então, estava tudo certinho ( $\mathrm{p} 9)$.

[...]Não vão colocar o ACS? A função do ACS vai ficar para nós? (p3).

[...] Esse cadastramento vai ser tipo uma convocação de todos os trabalhadores da SES, né? Você que vai na casa da pessoa, mesmo? (p11).

[...]Como que um centro de saúde que tem uma função tão tradicional vai colocar dois técnicos de saúde para assumir medicação, curativo, acolhimento, vacina e fazer cadastramento? A gente sabe que um técnico em uma equipe, ele tira férias, licença prêmio, ele adoece. Então, para a comunidade vai ficar muito desfalcado (p.8).

A concepção "ampliada” de modelos inclui a dimensão gerencial, dimensão organizativa e dimensão técnica assistencial. Sendo assim, as mudanças nos modelos de atenção ocorreriam com a interação das três dimensões, não necessariamente todas ao mesmo tempo ${ }^{34}$. Entre as variáveis afetantes pode-se destacar o não entendimento sobre as ferramentas tecnológicas e sua complexidade na APS. Apesar da ESF se propor a ser uma forma de reorientação do modelo assistencial, sendo prioritária e de caráter substitutivo em relação à rede de atenção básica tradicional, devendo atuar no território sob sua responsabilidade com foco na família e na 
comunidade $^{5}$, ainda existem dificuldades para compreensão do modelo ESF como efetivo e resolutivo na perspectiva de integração das redes de saúde, tal afirmação corrobora com outros achados na literatura ${ }^{35}$.

[...]Eu atendo em média 40 pessoas por dia, 20 pela manhã e 20 à tarde. E os enfermeiros quando estão no acolhimento umas 20 ou 30 pessoas. Então é inviável, porque isso não é nem acolhimento e nem triagem. Nós estamos sobe pressão. Porque esse só modelo de ESF só começou há um ano, né? Porque o que eu ouço foi ter gerado sobrecarga que antes era menos (p15).

As dificuldades de entender o papel de protagonista da APS envolvem as dimensões políticas, culturais e técnicas. Reconhecer que a hegemonia dos sistemas fragmentados de atenção à saúde, voltados prioritariamente para a atenção às condições agudas e aos eventos agudos das condições crônicas está na base da desvalorização da APS, o que é fortalecido por um sistema de pagamento por procedimentos baseado na densidade tecnológica dos diferentes serviços. Os trabalhadores têm foco em procedimentos e técnicas engessadas e, por vezes, esquecem-se que as dores de cabeça, a hiperglicemia ou a pressão alta é quase sempre ocasionada por questões sociais e de vulnerabilidade, só quando se entra no território que se consegue ver e perceber as necessidades ${ }^{36}$.

[...] mas, é assim, na ESF, se a pessoa não é cadastrada eles não atendem (p9).

[...]É aí que está a diferença. Neste modelo (biomédico) em que a gente estar, não tem isso. Cadastrado ou não o sujeito tem que ser atendido. Uma questão outra questão no modelo de ESF, se chega uma demanda não cadastrada, ele não é atendido. Ele vem para gente, encaminhado para nosso modelo (biomédico) (p8).

Esmeraldo et al. (2017) ${ }^{22}$ em seus estudos compararam a mudança de modelo tradicional para de ESF no Estado de Fortaleza-CE. Observou-se que as maiores dificuldades de implantação da ESF são os estigmas e as dificuldades em operacionalizar as práticas, e que a mudança não deveria vir de forma espontânea com única responsabilidade dos trabalhadores, pois se entende que se há uma hegemonia do modelo tradicional é porque os gestores, usuários e a sociedade como um todo é curativista, ou seja, biomédica. Transformar e implantar a ESF devem envolver a todos, principalmente na sua construção, de modo que traga uma carteira de serviços em conformidade com a capacidade técnica, de infraestrutura e a necessidade da população ${ }^{22}$.

Entre as dificuldades mencionadas entre os profissionais que trabalharam no modelo 
tradicional e que passaram pelas oficinas está o manejo em casos que exigem conhecimento em: ginecologia, pediatria, psiquiatria, entre outros. Apesar disso, entende-se, principalmente por meio dos Cadernos da Atenção Básica $n^{\circ} 32$ (Atenção de pré-natal de baixo risco), CAB $\mathrm{n}^{\circ} 30$ (Procedimentos), CAB n 25 (Doenças respiratórias ou crônicas), entre vários outros documentos oficiais, que casos que não exigem intervenção especializada, ou seja, aqueles que os profissionais têm capacidade de manejar após sua formação básica, esse atendimento deve ser feito na APS, além da atribuição de acompanhamento junto à atenção secundária e/ou terciária em casos que exigem esse tipo de atendimento ${ }^{4}$.

[...]A estratégia de saúde da família está propondo que os médicos fazem ginecologia, pediatria e outros serviços; eu já tenho 35 anos, pegar um RN, eu poderia ter uma pediatra para me ajudar. É joga a peteca nas mãos dos médicos? Agora, você tem uma habilitação de 120 horas para três especialidades? Eu acho que causa um risco para profissional, para a população e para a Secretária de Saúde, que vai responder por isso(p25).

Particularmente a transição vivenciada no DF sustenta a ideia de que especialistas focais não compõem a equipe mínima, fato que tem deslocado os profissionais especialistas para os níveis de atenção secundário e terciário. Com destaque para as mudanças no processo de trabalho e a organização profissional que a transição preconiza. Isto porque os profissionais em transição, habituados a uma dinâmica de trabalho, muitas vezes, precisam integrar-se em outra equipe, outro espaço físico e, principalmente, reestruturar a forma de atendimento ao usuário, o que acarreta resistência e descontentamento profissional ${ }^{36}$.

O modelo tradicional biomédico ainda é defendido pelos trabalhadores que participaram da oficina, porém foi possível identificar que a maioria dos participantes possuía uma concepção equivocada e que durante a realização das oficinas foi possível notar a transformação de opiniões. O modelo ainda é reforçado pelos trabalhadores por evidenciar e fortalecer a falsa cultura de assistencialismo pontual, visando unicamente a doença e não a pessoa ${ }^{22}$. Umas das problemáticas desse modelo é a automatização que causa desinteresse pela promoção da saúde, o que resulta na diminuição da qualidade do trabalho. O trabalho mecanizado cumprido sob as custas e por vigilância controladora visa apenas a produtividade e não as pessoas em seus contextos. A falta de autonomia profissional também é fator a ser considerado nesse modelo, uma vez que na saúde 
acontecem muitos imprevistos nos quais o trabalhador precisa tomar decisões, eximindo-se da criatividade e do próprio ato de improvisar diante das diversas realidades ${ }^{17}$.

\section{CONSIDERAÇÕES FINAIS}

Este estudo trouxe reflexões sobre as questões e desafios de implementação da ESF no DF, como modelo a ser priorizado em todos os equipamentos da APS. A coexistência e concorrência desde modelo e do modelo tradicional biomédico provocaram muito tempo barreiras de acesso aos serviços primários do SUS. Verificou-se de antemão que a mudança é progressiva e não depende unicamente de um agente, mas dos usuários e gestores.

A questão do distanciamento da gestão de saúde foi um ponto recorrente por todos os quatro grupos das oficinas de sensibilização. O processo de trabalho sendo antagônico ao preconizado pela ESF tem facilitado a separação entre trabalhadores e gestão, contribuindo para a falta de participação daqueles, quanto da tomada de decisões, um fator considerado muito importante. A automatização do processo de trabalho é vista pelos trabalhadores como ponto positivo, o que contraria a literatura, que aponta para ações reflexivas de caráter crítico. Há centralidade na doença e não na pessoa. Os trabalhadores identificaram como um problema, no entanto, seus discursos práticos voltam-se apenas para a queixa-conduta, desarticulando a proposta do acolhimento e vínculo. A partir da construção de espaço de diálogo e formação de colegiados com os profissionais, pode-se estreitar de forma qualitativa a comunicação entre os trabalhadores e a gestão, assim como a instituição de fórum virtual para troca de experiências.

Apesar de não poder ser extrapolada para outros grupos de trabalhadores, o fato de que as dificuldades enfrentadas no processo de consolidação da ESF perpassam não apenas os trabalhadores que estão iniciando sua inserção neste modelo, mas também aqueles que já trabalham nesta lógica. Faz-se necessário, portanto, avaliar a necessidade de ampliação das estratégias de educação continuada e permanente com os profissionais de saúde, uma vez que ações restritas a um curto período não se mostraram efetivas neste estudo, mesmo não sendo seu foco. Durante as 
oficinas de sensibilização, os trabalhadores fizeram referência à falta da comunicação com a gestão, devido à fragmentação e o isolamento. A passagem de informações e a falta de orientações e construções coletivas foram apontados como questões a serem melhoradas.

O retratado nos discursos dos trabalhadores não se identificou com o processo de mudança do modelo de atenção à saúde. Fica expresso nos quatro grupos que o desconhecimento de como foi planejado o ConvertDF causou angústias e frustrações as quais poderiam ser amenizadas com o envolvimento colaborativo, participativo e de desenvolvimento de ações no processo desde a elaboração até a implementação. Houve certo sentimento de exclusão, com significado muito importante, sobre invalidação e o descrédito dos trabalhadores com a gestão local.

Assim, a mudança de modelo de atenção à saúde deve vir de forma que acompanhe melhorias na estrutura física, abastecimento de insumo e a segurança de prover materiais essenciais para funcionamento com dignidade e qualidade. Sugere-se ainda que o problema não está na falta de educação permanente ou contínua, e sim no envolvimento gestão-trabalhador-usuário. Os gestores devem apropriar-se de outros métodos práticos como, por exemplo, a metodologia da problematização e de tutoria para alcançar, a partir de ações do cotidiano, as mudanças necessárias, objetivando a participação coletiva, democracia e ações horizontalizadas.

\section{REFERÊNCIAS BIBLIOGRÁFICAS}

1. CAMPOS, Gastão Wagner de Sousa; Guerrero, André Vinicius Pires. Manual de práticas de atenção básica: saúde ampliada e compartilhada. São Paulo, HUCITEC, 2008. p.132-153, graf. Saúde em debate, 190, p.

2.STARFIEL, D.B. Atenção Primária: Equilíbrio entre Necessidades de Saúde, serviços e tecnologia. 1.ed. Brasília: UNESCO, Ministério da Saúde, 2002.

3. BRASIL. Ministério da Saúde. Secretaria de Atenção à Saúde. Departamento de Atenção Básica. Política Nacional de Atenção Básica. Departamento de Atenção Básica. Brasília: Ministério da Saúde, 2012. 110 p. 
4. BRASIL. Ministério da Saúde. Secretaria de Atenção à Saúde. Política Nacional de Humanização da Atenção e Gestão do SUS. Clínica ampliada e compartilhada. Brasília: Ministério da Saúde, 2009. 64 p.: il. color. - (Série B. Textos Básicos de Saúde).

5. BRASIL. Portaria $n^{\circ}$ 2436, de 21 de setembro de 2017. Aprova a Política Nacional de Atenção Básica, estabelecendo a revisão de diretrizes para a organização da Atenção Básica, no âmbito do Sistema Único de Saúde (SUS). Diário Oficial da União, 22 set., 2017.

6. DISTRITO FEDERAL. Portaria $\mathrm{n}^{\circ}$ 77, de 14 de fevereiro de 2017. Estabelece a Política de Atenção Primária à Saúde do Distrito Federal. Diário Oficial do Distrito Federal, Brasília, DF, no 33, Seção I, 15 fev. 2017. p. 4-7.

7. CORREA, Daniel Seabra Resende Castro et al. Movimentos de reforma do sistema de saúde do Distrito Federal: a conversão do modelo assistencial da Atenção Primária à Saúde. Ciênc. saúde coletiva [online]. 2019, vol.24, n.6 [cited 2020-07-22], pp.2031-2041

8. SARRETA, F. O. Educação permanente em saúde para os trabalhadores do SUS [online]. São Paulo: Editora UNESP; São Paulo: Cultura Acadêmica, 2009. 248 p.

9. BRASIL. Conselho Nacional de Secretários de Saúde. Atenção Primária e Promoção da Saúde. Brasília: CONASS, 2007.

10. SARDINHA, P. L; CUZATIS, G. L; DUTRA, C. T; TAVARES, C. M. M; DANTAS C. A. C; ANTUNES, C. E. Educação permanente, continuada e em serviço: desvendando seus conceitos. Revista eletrônica trimestral de enfermagem,2013.

11. NEVES, V. F. A. Pesquisa-ação e Etnografia: Caminhos Cruzados. Pesquisas e Práticas Psicossociais, v. 1, n. 1, São João del-Rei, jun. 2006.

12. TANAJURA, L. L. C; BEZERRA, A.C. Pesquisa-ação sob a ótica de René Barbier e Michel Thiollent: aproximações e especificidades metodológicas. Rev.Eletrônica Pesquiseduca, Santos, v. 07, n. 13, p.10-23, jan.-jun. 2015

13. GAlVAO, M. C.; PlUYE, P.; RICARTE, I. Métodos de pesquisa mistos e revisões de literatura mistas: conceitos, construção e critérios de avaliação. InCID: Revista de Ciência da 
Informação e Documentação, v. 8, n. 2, p. 4-24, 4 out. 2018.

14.FIGUEIRÊDO, M.A.C., Nascimento, E.S., Silva, J.R., Souza V. Metodologia de oficina pedagógica: uma experiência de extensão com crianças e adolescentes. Revista Eletrônica Extensão Cidadã, V. 2, Paraíba, 2006.

15. SILVA, T. F.; ROMANO, V. F. O acolhimento e o Núcleo de Apoio à Saúde da Família no município do Rio de Janeiro: fragmentos, perspectivas e reflexões. Rev Bras Med Fam Comunidade. Rio de Janeiro: v. 10, n. 34, p.1-7, jan-mar., 2015.

16. FONTANA, Karine Cardoso; LACERDA, Josimari Telino de; MACHADO, Patrícia Maria de Oliveira. O processo de trabalho na Atenção Básica à saúde: avaliação da gestão. Saúde debate, Rio de Janeiro, v. 40, n. 110, p. 64-80, Sept. 2016.

17.ABRAHÃO, A. L. Atenção Primária e o processo de trabalho em saúde. Informe-se em promoção da saúde, Rio de Janeiro, v. 3, n. 1. p. 1-3. jan-jun. 2007.

18. CAMPOS, Gastão Wagner de Sousa. Equipes de referência e apoio especializado matricial: um ensaio sobre a reorganização do trabalho em saúde. Ciênc. saúde coletiva, Rio de Janeiro, v. 4, n. 2, p. $393-403,1999$.

19. GUIZARDI, Francini Lube; CAVALCANTI, Felipe de Oliveira Lopes. O conceito de cogestão em saúde: reflexões sobre a produção de democracia institucional. Physis, Rio de Janeiro, v. 20, n. 4, p. 1245-1265, Dec. 2010.

20. BRASIL. Conselho Nacional de Secretários de Saúde. As Conferências Nacionais de Saúde: Evolução e perspectivas. / Conselho Nacional de Secretários de Saúde. - Brasília: CONASS, 2009. 21. CAMPOS, G. W. S.; DOMITTI, A. C. Apoio Matricial e equipe de referência: uma metodologia para gestão do trabalho interdisciplinar em saúde. Cad. Saúde Pública. Rio de Janeiro, v. 23, n. 2, p. 399-407, 2007.

22. ESMERALDO, G. R. O. V; OLIVEIRA, L. C; FILHO, C. E. E. F; QUEIROZ, D. M; Tensão entre o modelo biomédico e a estratégia saúde da família: a visão dos trabalhadores de saúde. Rev. APS. 2017 jan/mar; 20(1): 98 - 106. 
23. GOTTEMS, Leila Bernarda Donato et al. O Sistema Único de Saúde no Distrito Federal, Brasil (1960 a 2018): revisitando a história para planejar o futuro. Ciênc. saúde coletiva, Rio de Janeiro, v. 24, n. 6, p. 1997-2008, June 2019.

24. FIGUEIREDO, E. N; A Estratégia Saúde da Família na Atenção Básica do SUS. Universidade Federal de São Paulo - UNA-SUS/UNIFESP,2012.

25.SANTOS, Debora de Souza, Mishima, Silvana Martins e Merhy, Emerson EliasProcesso de trabalho na Estratégia de Saúde da Família: potencialidades da subjetividade do cuidado para reconfiguração do modelo de atenção. Ciência \& Saúde Coletiva [online]. 2018, v. 23, n. 3 [Acessado 23 julho 2020], pp. 861-870.

26.CAMPOS, Gastão Wagner de Sousa. O anti-Taylor: sobre a invenção de um método para cogovernar instituições de saúde produzindo liberdade e compromisso. Cad. Saúde Pública, Rio de Janeiro, 14(4):863-870, out-dez, 1998.

27.SOUSA MF. O PSF nos grandes centros urbanos: o passado nos condena? In: Sousa MF, organizador. Os sinais vermelhos do PSF. São Paulo: Hucitec; 2002. p. 23-33.

28. Carvalho SR, Cunha GT. A gestão da atenção na saúde: elementos para se pensar a mudança da organização na saúde. In: Campos GWS, Minayo MCS, Akerman M, Drumond Junior M, Carvalho YM, organizadores. Tratado de Saúde Coletiva. Rio de Janeiro: Fiocruz; 2006. p. 837-867

29. BRASIL. Ministério da Saúde. Secretaria de Atenção à Saúde. Departamento de Atenção Básica. Caderno de Atenção Básica (CAB) 28 - Volume I: Acolhimento à demanda espontânea Brasília, 2013a.

30. BRASIL. Ministério da Saúde. Secretaria-Executiva. Núcleo Técnico da Política Nacional de Humanização. HumanizaSUS: Política Nacional de Humanização: a humanização como eixo norteador das práticas de atenção e gestão em todas as instâncias do SUS. Brasília: Ministério da Saúde, 2004. 20 p. 
31. NORA, C.R.D.N.; JUNGES, J.R. Política de humanização na atenção básica: revisão sistemática. Rev Saúde Pública, v. 47, n. 6, p. 1186-200, 2013.

32. SILVA, J. M. da; CALDEIRA, A. P. Modelo assistencial e indicadores de qualidade da assistência: percepção dos profissionais da atenção primária à saúde. Cad. Saúde Pública, Rio de Janeiro, v. 26, n. 6, p. 1187-1193, 2010.

33. GARUZI, M. et al. Acolhimento na estratégia saúde da família: revisão integrativa. Revista Panamericana de Salud Publica-pan American Journal of Public Health. Washington: Pan Amer Health Organization, v. 35, n. 2, p. 144-149, 2014.

34. TEIXEIRA, Carmen Fontes; SOLLA, Jorge Pereira. Modelos de Atenção à Saúde Promoção, Vigilância e Saúde da Família, Salvador, 2006.

35. COSTA GD, Cotta R.M.; Ferreira M.L.S. Reis JR, Franceschini SCC. Saúde da família: desafios no processo de reorientação do modelo assistencial. Rev Bras Enferm 2009; 62:113-8

36. MENDES, E. V. As redes de atenção à saúde. Minas Gerais: Ciência \& Saúde Coletiva, v. 15, n.5, p. 2297-2305, 2010.

37. BRASIL. Ministério da Saúde. Secretaria de Atenção à Saúde. Departamento de Atenção Básica. Política Nacional de Atenção Básica. Departamento de Atenção Básica. Brasília: Ministério da Saúde, 2012. 110 p.

38. DISTRITO FEDERAL. Portaria $\mathrm{n}^{\circ} 78$, de 14 de fevereiro de 2017. Regulamenta o art. 51 da Portaria n 77, de 2017, para disciplinar o processo de conversão da Atenção Primária à Saúde do Distrito Federal ao modelo da Estratégia Saúde da Família. Diário Oficial do Distrito Federal, Brasília, DF, no 33, Seção I, 15 fev. 2017. p. 7-8. 